\title{
On the Uniqueness of Space-Time Spectra and Synoptic Maps Derived from Polar-Orbiting Satellite Data
}

\author{
By Murry L. Salby \\ Department of Astrophysical, Planetary and Atmospheric Sciences, \\ University of Colorado, Campus Box 391, Boulder, CO 80309, USA \\ Yoshikazu Hayashi \\ Geophysical Fluid Dynamics Laboratory/NOAA, P.O. Box 308, \\ Princeton, NJ 08542, USA \\ (Manuscript received 5 July 1985, in revised form 8 October 1985)
}

\begin{abstract}
Two methods for deriving space-time spectra from asynoptic satellite data, the frequency transform method (Hayashi, 1983a) and the asynoptic space-time transform method (Salby, 1982a) are shown to be equivalent. That is they give identical spectra and have identical aliasing characteristics. When asynoptic sampling conditions are satisfied, this linear transformation is unique and recovers the correct spectrum over wavenumber and frequency for a satellite observed field. Moreover the synoptic mapping of asynoptic data, as implied by this operation, is the only linear transformation capable of extracting the true synoptic behavior from asynoptic measurements. Other procedures used to derive synoptic behavior must reduce to this transformation if they are to consistently recover the correct structure and evolution.
\end{abstract}

\section{Introduction}

Two approaches for deriving space-time spectra from asynoptic polar-orbiting satellite data have recently been reviewed by Hayashi $(1983 a, b)$. The first of these is a rederivation of the asynoptic space-time transform, originally developed in Salby (1982a, b). The second generalizes the wavenumber transform procedure, devised by Hayashi (1980), in order to accommodate irregularly spaced combined-node data (Salby, 1982a). While both approaches derive a space-time spectrum from asynoptic data, the wavenumber transform procedure requires a pre-interpolation from irregular asynoptic coordinates to a regular longitude-latitude grid. This interpolation introduces a varying degree of error dependent upon the behavior of the field being observed (Hayashi, 1983b). Only the asynoptic space-time transform embodies a unique mapping between asynoptic and synoptic coordinates, and in so doing retrieves the true space-time spectrum when asynoptic sampling conditions are met. The latter are given by the Asynoptic Sampling Theorem (Salby, 1982a) and define the frequency of sampling required to resolve a field's behavior, and thereby eliminate aliasing.

In this note we show that the frequency transform procedure described by Hayashi (1983a) is equivalent to the asynoptic transform method developed in Salby (1982a). Although their derivations may differ, the two derived transformations are the same. They give identical spectra and have the same aliasing characteristics. We also show that 
this transformation between asynoptic measurements and synoptic quantities is unique and that the "exact" synoptic mapping of asynoptic data which it implies (Salby, 1982b) is likewise unique when the aforementioned sampling conditions are satisfied.

\section{Uniqueness of asynoptic transformation}

In his derivation, Hayashi (1983a) introduces a Galilean transformation to derive space-time spectra from asynoptic observations, whereas Salby (1982a) makes use of an asynoptic coordinate transformation. We demonstrate here that the ultimate results of these two operations are identical. That is, they are merely different ways of writing the same transformation from asynoptic data. In so doing we show that this transformation, which recovers synoptic quantities "exactly" in the absence of sampling errors (i.e. when asynoptic sampling conditions are met), is intrinsic to the asynoptic sampling of a satellite borne instrument. It is the only transformation capable of extracting the correct synoptic behavior under such conditions from asynoptic measurements.

In both Salby (1982a) and Hayashi (1983a), a mapping between asynoptic data $\psi\left(\lambda_{n}, t_{n}\right)$ and the space-time Fourier spectrum $\Psi\left(m, \sigma_{k}\right)$ is defined. Here $\lambda_{n}$ and $t_{n}$ denote the longitude and time of the $n$-th sample point of the observed field $\phi$, and $m$ and $\sigma_{k}$ denote the wavenumber and frequency of the field's complex space-time spectrum $\Psi$ in the transform plane. The observed values may be arranged into an asynoptic data vector

$$
\boldsymbol{x}=\phi\left(\lambda_{n}, t_{n}\right),
$$

where $n$ denotes the $n$-th sample point, and similarly its transform arranged into a spacetime spectrum vector

$$
\boldsymbol{s}=\Psi\left(m, \sigma_{k}\right),
$$

where $m$ and $k$ denote the $m$-th and $k$-th wavenumber and frequency, respectively. In both cases, Salby (1982a) and Hayashi (1983a), the true space-time spectrum $s$, is correctly derived from the asynoptic input $\boldsymbol{x}$ via a sequence of linear operations, provided that the Asynoptic Sampling Theorem is satisfied. These transformations may be configured into the linear operator $\mathcal{L}$, such that

$$
\mathcal{L} \boldsymbol{x}=\boldsymbol{s},
$$

where $\boldsymbol{x}, \boldsymbol{s}$, and $\mathcal{L}$ are $N, N$, and $N^{2}$ dimensional, respectively. Thus $\mathcal{L}$ defines a mapping of the asynoptic data vector $\boldsymbol{x}$ into the space-time spectrum $\boldsymbol{s}$ for arbitrary input $\boldsymbol{x}$. Since the transformation which maps $\boldsymbol{x}$ into $s$ is linear, it may be shown that $\mathcal{L}$ is unique. Thus any two prescriptions correctly mapping $\boldsymbol{x}$ into $\boldsymbol{s}$ must be identical. This is now demonstrated.

Consider $N$ different sets of input which define $N$ linearly independent input vectors $\dot{x}^{j} ; j=1,2, \cdots N$. Each of these data samples contains $N$ data points and is presumed to satisfy the Asynoptic Sampling Theorem. That is the field has been adequately sampled; there are no unresolved spatial or temporal scales. This ensures that each input vector $\boldsymbol{x}^{j}$ contains sufficient information to determine the correct space-time spectrum $\boldsymbol{s}^{j}$.

Then (2) must hold for each input set

$$
\mathcal{L} \boldsymbol{x}^{j}=\boldsymbol{s}^{j} \quad j=1,2, \cdots N,
$$

which gives the following $N^{2}$ equations:

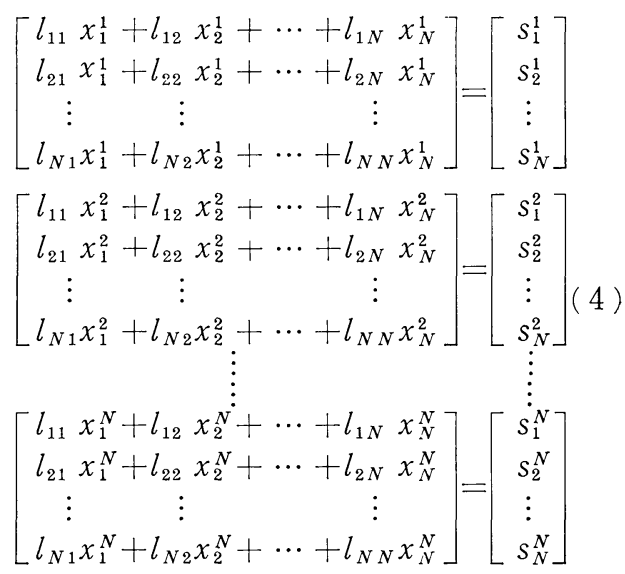

Equations (4) may be reconfigured into $N$ systems of equations, each involving a single row of the operator $\mathcal{L}$ :

$$
\boldsymbol{\chi} \lambda^{n}=\boldsymbol{\sigma}^{n}, \quad n=1,2, \cdots N
$$

where 


$$
\begin{gathered}
\boldsymbol{\chi}=\left[\begin{array}{cccc}
x_{1}^{1} & x_{2}^{1} & \cdots \cdots & x_{N}^{1} \\
x_{1}^{2} & x_{2}^{2} & \cdots \cdots & x_{N}^{2} \\
\vdots & \vdots & & \vdots \\
x_{1}^{N} & x_{2}^{N} & \cdots \cdots & x_{N}^{N}
\end{array}\right] \\
\boldsymbol{\lambda}^{n}=\left[\begin{array}{c}
l_{n 1} \\
l_{n 2} \\
\vdots \\
l_{n N}
\end{array}\right] \quad \boldsymbol{\sigma}^{n}=\left[\begin{array}{c}
s_{n}^{1} \\
s_{n}^{2} \\
\vdots \\
s_{n}^{N}
\end{array}\right]
\end{gathered}
$$

These, in turn, may be consolidated into the single block diagonal system:

$$
\hat{x} \lambda=\sigma,
$$

where

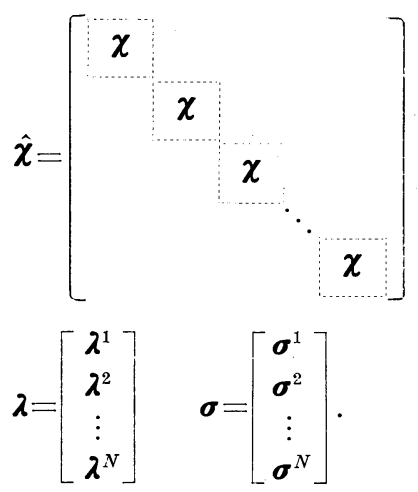

But now since the vectors $\boldsymbol{x}^{j}$ are linearly independent, $\|\hat{\boldsymbol{\chi}}\| \neq 0$. Hence, (6) has a unique solution $\lambda$, and thus from (5) the transformation $\mathcal{L}$ is uniquely determined. ${ }^{1)}$

\section{Conclusion and Remarks}

We have shown that the transformation between asynoptic data and its "true" spacetime spectrum is unique, provided that the field has been adequately sampled. Symbolically this operation may be written

$$
\Psi=\mathcal{S}_{a} \boldsymbol{\psi}_{a},
$$

where $\boldsymbol{\phi}_{a}$ now denotes the asynoptic data, $\Psi$ the true space-time spectrum, and $\mathcal{S}_{a}$ represents the asynoptic form of the spacetime transform (Salby, 1982a; equivalent to $\boldsymbol{\psi}, \boldsymbol{s}$, and $\mathcal{L}$ in Sec. 2). Perhaps of greater

1) Since the $N$ linearly independent vectors $\boldsymbol{x}^{j}$ span the $N$-dimensional space of possible data, it follows that any input vector can be constructed by suitable combination of these, and thus the transformation and previous ideas go through as before. importance is the fact that if the Asynoplic Sampling Theorem is satisfied, a field's behavior in physical space is uniquely related to its space-time spectrum. Thus the synoptic mapping of asynoptic data, as may be recovered by unraveling $\Psi$ synoptically (Salby, 1982b; Hayashi, 1983b) is also unique. The synoptic behavior may be obtained by simply applying the synoptic form of the inverse space-time transform to the Fourier spectrum $\Psi$. Thus from (7)

$$
\boldsymbol{\psi}_{s}=\left(\mathcal{S}_{s}^{-1} \cdot \mathcal{S}_{a}\right) \boldsymbol{\psi}_{a},
$$

where $\boldsymbol{\phi}_{s}$ is the synoptic data vector (in practice a sequence of synoptic maps) and $\mathcal{S}_{s}^{-1}$ denotes the synoptic form of the inverse space-time transform. The operation $\left(\mathcal{S}_{s}^{-1} \cdot \mathcal{S}_{a}\right)$, which maps a series of asynoptic measurements into the "correct" sequence of synoptic maps is unique. That is, under conditions of the Asynoptic Sampling Theorem, there is only one such transformation capable of recovering the true synoptic behavior from a series of asynoptic measurements. The operation which extracts this structure and evolution, $\left(\mathcal{S}_{s}^{-1} \cdot \mathcal{S}_{a}\right)$, is intrinsic to the asynoptic sampling and is not tied to say particular method of derivation.

In practice, the conditions of the Asynoptic Sampling Theorem are never perfectly satisfied. Nevertheless even in circumstances where they are strongly violated, two transformations which would recover the true spectrum if sampling conditions were met are still identical and have the same aliasing characteristsics when the sampling is inadequate.

The uniqueness of the synoptic mapping (8) is of profound importance for applications. In practice satellite data may be mapped by a number of methods of varying sophistication. Each of these may be thought of as some transformation of asynoptic measurements to synoptic coordinates. Implicitly each of these operations is a form of space-time interpolation. If the sampling conditions are met, that is the asynoptic data contain sufficient information, then the synoptic behavior can in principle be recovered. From the previcus discussion it follows that only if these 
operations reduce to the transformation $\left(\mathcal{S}_{s}^{-1} \cdot \mathcal{S}_{a}\right)$, will the derived sequence of synoptic maps consistently equal the correct behavior of the observed field.

\section{Acknowledgements}

This work was supported in part by NASA contract NAGW-772.

\section{References}

Hayashi, Y., 1980: A method of estimating spacetime spectra from polar-orbiting satellite data. J. Atm. Sci., 37, 1385-1392.
, 1938a: Modified methods of estimating space-time spectra from polar-orbiting satellite data. Part I: The frequency transform method. J. Meteor. Soc. Japan, 61, 254-262. , 1983b: Modified methods of estimating space-time spectra from polar-orbiting satellite data. Part II: The wavenumber transform method. J. Meteor. Soc. Japan, 61, 263-267.

Salby, M., 1982a: Sampling theory for asynoptic satellite observations. Part I: Space-time spectra, resolution, and aliasing. J. Atm. Sci., 39, $2577-2600$.

1982b: Sampling theory for asynoptic satellite observations. Part II: Fast Fourier synoptic mapping. J. Atm. Sci., 39, 2601-2614.

\title{
極軌道衛星データから求められる時空間スペクトルと綜観図の唯一性について
}

\author{
M. L. Salby \\ University of Colorado, U.S. A. \\ 林良 一 \\ GFDL/NOAA, U.S.A.
}

非綜観的な衛星データから時空間スペクトルを求める二つの方法（振動数变換法, Hayashi, 1983a; 非綜観 的時空間変換法, Salby, 1982a) は同等であることを示した。すなわちこれらの方法は同一のスペクトルを与 え, 同一の aliasing 特性を持つ。非綜観的な sampling condition が満たされている時, この一次变換は唯一 で, 衛星により観測された場に対して正しく振動数一波数スペクトルを復元する。更に, この操作が意味する ように非綜観的データの綜観的 mapping は非綜観的な測定から真の綜観的振子舞いを抽出できる唯一の一次 変換である。もし他の手続で綜観的振子舞いを求め正しい構造と変化を矛盾なく復元できるとしたら, その手 続はこの方法に帰着しなければならない。 